\title{
UMA EXPERIÊNCIA DIDÁTICA DE CORROSÃO USANDO COLORIMETRIA VISUAL
}

\author{
Bárbara Bidoia Bidetti, Priscila Aoki Balthazar, Ednilson Luiz Silva Vaz, Eduardo Norberto Codaro e Heloisa Andréa \\ Acciari* \\ Departamento de Física e Química, Faculdade de Engenharia de Guaratinguetá, Universidade Estadual Paulista, Av. Dr. Ariberto \\ Pereira da Cunha, 333, 12516-410 Guaratinguetá - SP, Brasil
}

Recebido em 22/2/11; aceito em 12/9/11; publicado na web em 8/11/11

\begin{abstract}
A TEACHING EXPERIMENT OF CORROSION USING VISUAL COLORIMETRY. In this paper, a simple and rapid method of evaluating galvanized steel sheet corrosion in $\mathrm{CuSO}_{4}$ solution, as an experimentation proposal for corrosion teaching. Galvanized steel corrosion is present in tanks and tubing by leading of natural or industrial waters which contain soluble copper compounds. This was the rationale for choosing the $\mathrm{Cu}^{2+}$ ions solution as an oxidizing agent. The method principle is based on visual colorimetry because the used oxidant has an intense blue color. Thus, a change in its concentration as a result of the corrosive process can be followed by a color intensity change in the solution thereby allowing evaluation of the corrosion rate.
\end{abstract}

Keywords: chemistry education; corrosion; social interaction.

\section{INTRODUÇÃO}

A corrosão generalizada é um processo natural envolvendo reações de oxidação e de redução (redox), que ocorrem simultaneamente em toda a superfície de um material metálico em contato com um agente oxidante, resultando numa diminuição da espessura. Um dos métodos mais antigos e difundidos para estudar a velocidade de corrosão (taxa de corrosão) em meio líquido é o ensaio de imersão. ${ }^{1}$ Mediante este método pode ser avaliada a perda de massa do material, a quantidade de matéria dissolvida ou o volume de gás liberado durante a corrosão a diferentes de tempos de imersão. ${ }^{2}$ Em certos casos, quando o agente oxidante apresenta coloração, a variação da sua concentração pode ser acompanhada pela aplicação sucessiva de um método colorimétrico, associando as cores mais intensas com soluções mais concentradas. Para demonstrar a viabilidade deste método estudou-se a corrosão de uma chapa de aço revestida com zinco (aço galvanizado) em solução de $\mathrm{CuSO}_{4}$ por colorimetria visual.

Diferentes processos podem ser utilizados no revestimento de superfícies metálicas com zinco: a galvanização por imersão a quente ou zincagem a fogo, a eletrodeposição ou zincagem a frio e, também, a metalização ou aspersão térmica, sendo o primeiro mais utilizado por ser o mais econômico. ${ }^{3}$

O processo de imersão a quente consiste na imersão do aço em um banho de zinco fundido $\left(445\right.$ a $\left.465^{\circ} \mathrm{C}\right)$. Durante a imersão ocorre um processo de difusão atômica, de modo a formar uma camada de liga na superfície do aço, cuja composição varia através da espessura da camada, tornando-se progressivamente mais rica em zinco à medida que aumenta a espessura desta camada. $\mathrm{O}$ revestimento resultante é uniforme e apresenta uma espessura que varia entre 5 e $55 \mu \mathrm{m}$ quando o processo é contínuo (por exemplo, chapas que entram e saem do banho à velocidade constante) e entre 35 e $400 \mu \mathrm{m}$ quando descontínuo. Em particular, chapas assim revestidas são produzidas com diversos acabamentos superficiais, dentre eles o cristal normal e o cristal minimizado. As chapas com cristais normais apresentam brilho metálico e desenhos que parecem flores, consequência do livre crescimento dos cristais durante a solidificação. Estas chapas são utilizadas na construção civil sem

\footnotetext{
*e-mail: heloisa@feg.unesp.br
}

aplicação prévia de pintura. Por outro lado, as chapas galvanizadas com cristais minimizados apresentam uma superfície mais lisa e regular, o que é esteticamente mais adequado para aplicações que exijam pintura posterior.

A eletrodeposição é o processo pelo qual um revestimento de zinco é aplicado sobre a superfície do aço em uma célula eletroquímica contendo uma solução aquosa de sais de zinco. A deposição é feita mediante a aplicação de uma diferença de potencial entre a peça de aço (cátodo) e um ânodo de zinco, que garante a passagem de uma corrente contínua $\left(0,5\right.$ a $\left.50 \mathrm{~A} / \mathrm{cm}^{2}\right)$. Os eletrodepósitos são constituídos praticamente de zinco puro, não havendo reação significativa entre o aço e o zinco a temperaturas ordinárias. A vantagem deste método reside na obtenção de revestimentos leves com espessuras geralmente menores que $40 \mu \mathrm{m}$.

A metalização consiste na aspersão do zinco fundido sobre o aço através de uma pistola com um sistema de aquecimento, por chama oxiacetilênica ou por arco elétrico. Nestes processos, o zinco é fundido no bocal da pistola e impulsionado por um jato de ar comprimido. No impacto, as partículas metálicas se deformam formando plaquetas finas que aderem ao substrato, produzindo uma camada rugosa e porosa. Com este processo não é possível a obtenção de revestimentos muito finos, suas espessuras variam entre 50 e $200 \mu \mathrm{m} .{ }^{4,5}$

O material escolhido é amplamente utilizado pela indústria automotiva na fabricação de carrocerias e, também, na construção civil na forma de telhas, calhas, rufos, coifas e dutos, pelo fato da camada de zinco não alterar as propriedades mecânicas do aço, além de conferir proteção contra a corrosão atmosférica. No entanto, atmosferas poluídas contendo metais de transição, provenientes de indústrias metalúrgicas, ${ }^{6,7}$ podem provocar uma rápida deterioração desta camada. A oxidação destes metais pelo oxigênio ou ozônio conduz à formação de íons, os quais aparecem dissolvidos na água da neblina ou da chuva e, desta forma, entram em contato com os materiais metálicos. A corrosão do aço galvanizado também está presente em reservatórios e tubulações que conduzem águas naturais ou industriais que contêm compostos solúveis de cobre. ${ }^{8}$ Por estas razões, foi escolhida a solução de íons $\mathrm{Cu}^{2+}$ como agente oxidante e, também, por apresentar uma coloração azul intensa que permite acompanhar a diminuição da concentração, por meio da mudança de intensidade da cor no decorrer do tempo e, deste modo, avaliar a taxa de corrosão. 


\section{Fundamentação teórica}

A velocidade de uma reação mede quão rápido um reagente é consumido ou um produto é formado durante a reação. No entanto, esta informação é vaga, uma vez que a velocidade varia conforme as concentrações dos reagentes e dos produtos variam com o tempo. Uma possível solução para este problema é considerar a velocidade média (taxa média) de desaparecimento de um reagente num certo intervalo de tempo. ${ }^{9}$ Neste caso, a taxa média de corrosão do aço galvanizado em solução de $\mathrm{CuSO}_{4}$ foi determinada por colorimetria visual (Figura 1). O método consiste em comparar a olho nu as intensidades de cor que essa solução apresenta no decorrer do tempo com padrões de cor formados por soluções de concentrações conhecidas.

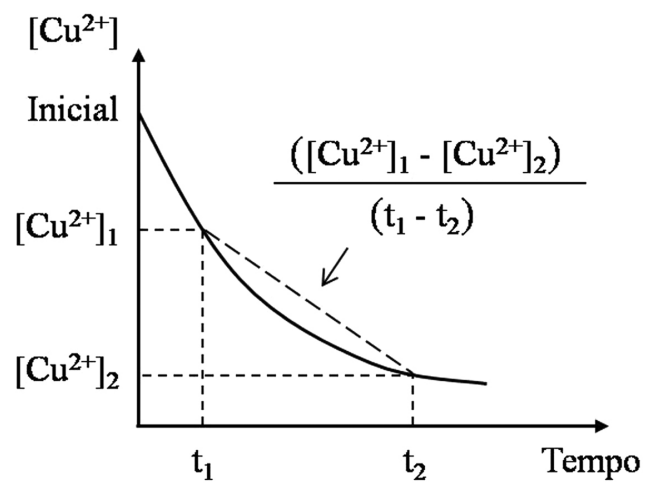

Figura 1. Determinação gráfica da taxa média de corrosão

Sabe-se que uma substância se mostra azul se absorver toda a luz, mas se refletir a componente azul. Também pode parecer azul por refletir todas as cores exceto a laranja, a cor complementar do azul. Isto também ocorre com a luz transmitida, como a luz que atravessa uma solução. Em particular, a solução que contém íons $\mathrm{Cu}^{2+}$ absorve luz na região do laranja do espectro e, por esta razão, parece azul . ${ }^{9}$

A resistência à corrosão do aço galvanizado aos meios naturais é atribuída a dois mecanismos: proteção por barreira, exercida pela camada de zinco que se interpõe entre o aço e o meio e, proteção catódica, diante de uma eventual falha nessa camada, o zinco é oxidado preferencialmente ao ferro do aço, formando uma película protetora branca de óxido, hidróxido (Equação 1), sais básicos ou neutros dependendo do $\mathrm{pH}$ do meio. ${ }^{8}$

$$
2 \mathrm{Zn}(\mathrm{s})+\mathrm{O}_{2}(\mathrm{~g})+2 \mathrm{H}_{2} \mathrm{O}(\mathrm{l}) \rightarrow 2 \mathrm{Zn}(\mathrm{OH})_{2}(\mathrm{~s})
$$

Como as soluções de sais de cobre(II) são ácidas (neste trabalho o pH foi 3,75), devido à hidrólise do cátion, esta película é dissolvida e a camada de zinco é novamente oxidada. Assim, a cor da solução se torna menos intensa à medida que o $\mathrm{Cu}^{2+}$ é consumido pela reação redox (Equação 2).

$$
\mathrm{Zn}(\mathrm{s})+\mathrm{Cu}^{2+}(\mathrm{aq}) \rightarrow \mathrm{Zn}^{2+}(\mathrm{aq})+\mathrm{Cu}(\mathrm{s})
$$

Quando a quantidade de zinco é insuficiente para proteger o aço, inicia-se a oxidação do ferro tornando a solução esverdeada (Equação 3).

$$
\mathrm{Fe}(\mathrm{s})+\mathrm{Cu}^{2+}(\mathrm{aq}) \rightarrow \mathrm{Fe}^{2+}(\mathrm{aq})+\mathrm{Cu}(\mathrm{s})
$$

Pelo exposto, fica claro que quanto maior a espessura da camada de zinco maior será a proteção do aço e serão necessárias maiores concentrações de agente oxidante para a dissolução total dessa camada. As chapas de aço galvanizado são comercializadas de acordo com a espessura da camada de zinco, recebendo uma numeração do 12 ao 32, conforme diminui a espessura média das chapas de 2,70 a $0,30 \mathrm{~mm}$. Para este ensaio foi selecionada uma chapa comumente usada na construção civil (chapa galvanizada no 24 ) a qual tem uma massa mínima (média da amostragem) de $350 \mathrm{~g}$ de $\mathrm{Zn} / \mathrm{m}^{2}$ e apresenta uma espessura média do revestimento (média da amostragem) de $0,049 \mathrm{~mm} .{ }^{10} \mathrm{Com}$ estas características, considerando um corpo-deprova (c-d-p) de $0,0033 \mathrm{~m}^{2}$ para ser imerso num volume de $40,0 \mathrm{~mL}$ de $\mathrm{CuSO}_{4}$, foi calculada, a partir da Equação 2, a concentração mínima desta solução necessária para dissolver totalmente a camada de zinco (Equação 4).

$\left[\mathrm{Cu}^{2+}\right]=(1,16 \mathrm{~g}$ de $\mathrm{Zn})(1 \mathrm{~mol}$ de $\mathrm{Zn} / 65,41 \mathrm{~g}$ de $\mathrm{Zn})(1 / 0,04 \mathrm{~L}) \approx$ $0,45 \mathrm{~mol} \mathrm{~L}^{-1}$

Com intuito de sistematizar o trabalho foi usada uma solução de $\mathrm{CuSO}_{4}$ 0,50 mol L-1 para preparar a solução de ataque e os padrões de cor por diluição.

\section{PARTE EXPERIMENTAL}

\section{Materiais e reagentes}

Os materiais e reagentes necessários para que cada grupo realize esta experiência são: 1 chapa galvanizada o 24 de 100 x 33 mm; 2 pissetas, uma com água destilada e outra com álcool; algodão; 1 pinça metálica; 2 buretas de $50 \mathrm{~mL} ; 1$ proveta de $50 \mathrm{~mL} ; 1$ funil de vidro; 12 béqueres de $50 \mathrm{~mL}$ da mesma marca; 1 relógio; 1 vidro de relógio; 1 lâmpada fluorescente tubular comum de potência entre 20 e $40 \mathrm{~W}$; solução de $\mathrm{CuSO}_{4} 0,50 \mathrm{~mol} \mathrm{~L}-1$.

\section{Preparação dos padrões de cor}

Para maior organização e aproveitamento da aula prática, recomenda-se a divisão dos alunos em grupos e que esta etapa seja realizada por cada grupo. Para tal fim, pegar 10 béqueres e, mediante duas buretas, uma para água destilada e outra para solução de $\mathrm{CuSO}_{4}$ 0,50 mol/L, preparar os padrões de acordo com a Tabela 1. As concentrações das soluções resultantes podem ser calculadas usando a Equação 5.

$$
\mathrm{C}_{\mathrm{i}} \times \mathrm{V}_{\mathrm{i}}=\mathrm{C}_{\mathrm{f}} \times \mathrm{V}_{\mathrm{f}}
$$

onde $\mathrm{C}_{\mathrm{i}}$ e $\mathrm{V}_{\mathrm{i}}$ são a concentração e o volume da solução inicial (concentrada), respectivamente, $C_{f}$ e $V_{f}$ são a concentração e o volume da solução final (diluída), respectivamente.

Tabela 1. Preparação dos padrões de cor

\begin{tabular}{ccc}
\hline $\begin{array}{c}\text { Volume de } \mathrm{H}_{2} \mathrm{O} \\
\text { destilada }(\mathrm{mL})\end{array}$ & $\begin{array}{c}\text { Volume de } \mathrm{CuSO}_{4} \\
0,50 \mathrm{~mol} / \mathrm{L}(\mathrm{mL})\end{array}$ & $\begin{array}{c}\text { Concentração final da } \\
\text { solução }(\mathrm{mol} / \mathrm{L})\end{array}$ \\
\hline 4,0 & 36,0 & 0,45 \\
8,0 & 32,0 & 0,40 \\
12,0 & 28,0 & 0,35 \\
16,0 & 24,0 & 0,30 \\
20,0 & 20,0 & 0,25 \\
24,0 & 16,0 & 0,20 \\
28,0 & 12,0 & 0,15 \\
32,0 & 8,0 & 0,10 \\
36,0 & 4,0 & 0,05 \\
40,0 & 0,0 & 0,00 \\
\hline
\end{tabular}




\section{Realização do ensaio}

Cada grupo deve trabalhar com um c-d-p, de modo que, no final do experimento, se propicie a discussão da taxa de corrosão. Primeiramente, posicionar os padrões de cor sobre uma superfície branca e de frente a uma lâmpada tubular fluorescente, como mostrado na Figura 2.

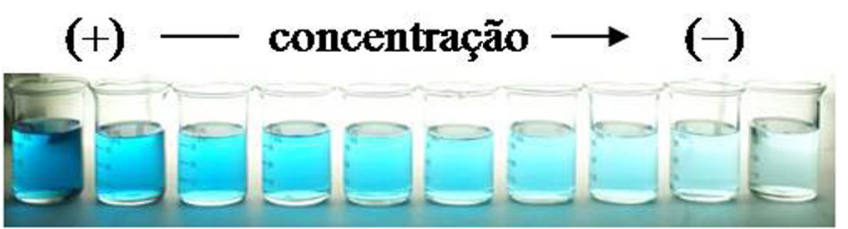

Figura 2. Padrões de cor iluminados com lâmpada fluorescente

A seguir, curvar o c-d-p formando um cilindro, de modo que possa ser introduzido dentro do béquer onde ocorrerá a reação. A limpeza da superfície do c-d-p será feita com um algodão umedecido com água destilada e, posteriormente, com outro umedecido com álcool. Após esse procedimento, manipular o c-d-p com uma pinça metálica e introduzi-lo no béquer. Utilizando uma proveta, medir $40,0 \mathrm{~mL}$ de solução de $\mathrm{CuSO}_{4}$ 0,45 mol/L, transferir para o béquer e começar a medida do tempo de imersão. A cada 5 min transferir de forma lenta esta solução para outro béquer, evitando que a dispersão de partículas de cobre metálico interfira na comparação visual com os padrões de cor. Em seguida, posicionar-se de frente aos padrões, a uma distância prefixada, de modo que a luz transmitida sempre percorra o mesmo caminho óptico. A seguir, intercalar este béquer entre os padrões até conseguir uma sequência coerente de cor. Contudo, três situações podem ocorrer: a cor da solução do béquer é aparentemente igual a um dos padrões; o béquer situa-se entre dois padrões, neste caso será considerada uma média de duas concentrações de íons $\mathrm{Cu}^{2+}$ entre os padrões; a solução torna-se esverdeada (presença de $\mathrm{Fe}^{2+}$ ) e não poderá ser comparada com os padrões, deverá ser descartada (Figura 3). Anotar esses valores de concentração na Tabela 2.

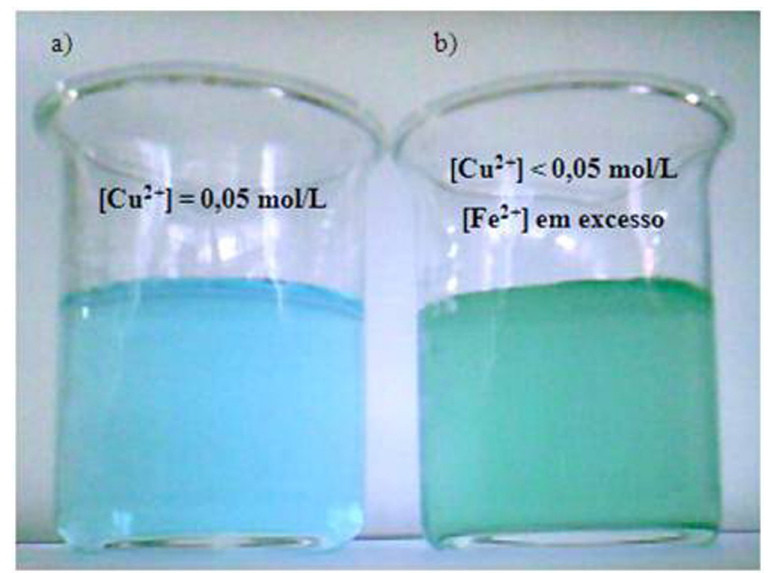

Figura 3. Comparação de cores: a) padrão 0,05 mol/L e b) solução após 30 min de imersão

Finalizado o experimento, retirar com uma pinça o c-d-p, colocálo sobre um vidro de relógio e deixá-lo secar ao ar. Transferir a solução de análise para um frasco de resíduos. Posteriormente, cada grupo deve colocar seus dados num gráfico (concentração de íons $\mathrm{Cu}^{2+}$ versus tempo), traçar a melhor curva que passe entre os pontos e, a partir dela, calcular as taxas médias de corrosão.
Tabela 2. Concentração de íons $\mathrm{Cu}^{2+}$ em função do tempo de imersão

\begin{tabular}{cc}
$\begin{array}{c}\text { Tempo de imersão }(\mathrm{t}) \\
(\min )\end{array}$ & $\begin{array}{c}\text { Concentração de íons } \mathrm{Cu}^{2+} \\
(\mathrm{mol} / \mathrm{L})\end{array}$ \\
\hline 0 & 0,450 \\
5 & 0,325 \\
10 & 0,225 \\
15 & 0,125 \\
20 & 0,075 \\
25 & 0,050 \\
30 & 0,025 \\
\hline
\end{tabular}

\section{DISCUSSÃO}

Nesta experiência os alunos podem constatar o fenômeno da corrosão generalizada. A Figura 4 apresenta o c-d-p antes (a) e depois da experiência (b). Pode-se observar que sua forma original foi preservada, sendo a principal diferença a formação de uma superfície esponjosa, com abundante depósito alaranjado de cobre metálico, no c-d-p corroído.

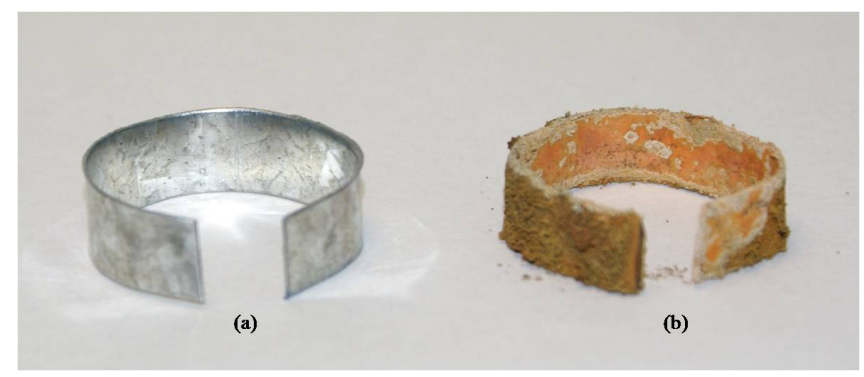

Figura 4. C-d-p antes a) e após b) o ensaio de corrosão

Uma análise detalhada dos valores de potenciais-padrão de redução, [ $\left.\mathrm{E}^{0}\left(\mathrm{Zn}^{2+} / \mathrm{Zn}\right)=-0,76 \mathrm{~V}\right],\left[\mathrm{E}^{0}\left(\mathrm{Fe}^{2+} / \mathrm{Fe}\right)=-0,44 \mathrm{~V}\right],\left[\mathrm{E}^{0}\left(\mathrm{Cu}^{2+} / \mathrm{Cu}\right)=\right.$ $+0,34 \mathrm{~V}]$ e $\left[\mathrm{E}^{0}\left(\mathrm{O}_{2} / \mathrm{H}_{2} \mathrm{O}\right)=+1,23 \mathrm{~V}\right]$, indica que $\mathrm{Zn}$ deve ser oxidado mais facilmente que $\mathrm{Fe} \mathrm{e} \mathrm{O}_{2}$ reduzido preferencialmente ao $\mathrm{Cu}$. Sendo assim, como explicar a redução do $\mathrm{Cu}$ sobre o aço galvanizado? No meio aquoso a concentração de $\mathrm{O}_{2}$ dissolvido é baixa $\left(2,86 \times 10^{-4}\right.$ $\mathrm{mol} / \mathrm{L} \mathrm{H}_{2} \mathrm{O}$ à $25{ }^{\circ} \mathrm{C}$ e $\left.0,22 \mathrm{~atm}\right)^{9}$ e este é rapidamente consumido durante o processo de corrosão, tendo que ser reposto naturalmente através da superfície da solução. Como a difusão de $\mathrm{O}_{2}$ é lenta e a concentração de $\mathrm{Cu}^{2+}$ é comparativamente maior $(0,45 \mathrm{~mol} / \mathrm{L})$, este último passa a ser reduzido pelo $\mathrm{Zn}$.

A Figura 5 mostra a curva experimental $\left[\mathrm{Cu}^{2+}\right]$ vs tempo, cuja inclinação ou coeficiente angular para cada intervalo de tempo define a taxa média de corrosão. Observa-se que esta taxa não é constante e tende a diminuir no decorrer do tempo, por quê? No início, a concentração de $\mathrm{Cu}^{2+}$ é grande e a reação de corrosão se processa rapidamente, de acordo com o princípio fundamental da cinética química, porém, esta reação vai ficando cada vez mais lenta à medida que essa concentração diminui em virtude da reação redox (Equação 2).

Mas, aonde o $\mathrm{Cu}$ é depositado? A camada de Zn é microscopicamente heterogênea existindo diferentes sítios para a oxidação, uns mais ativos que outros. O Cu será depositado inicialmente nos sítios catódicos do revestimento de zinco e continuará nos sítios catódicos do ferro. O depósito de Cu sobre o Zn ou Fe ocasionará outro fenômeno, a corrosão galvânica, a qual aconteceria mesmo que a solução de $\mathrm{Cu}^{2+}$ fosse o reagente limitante. Neste caso, a reação anódica continuaria sendo a oxidação de $\mathrm{Zn}$ ou $\mathrm{Fe}$ e, a reação catódica, a redução do $\mathrm{O}_{2}$ preferencialmente sobre o $\mathrm{Cu}$ (Equação 6), pelo fato 


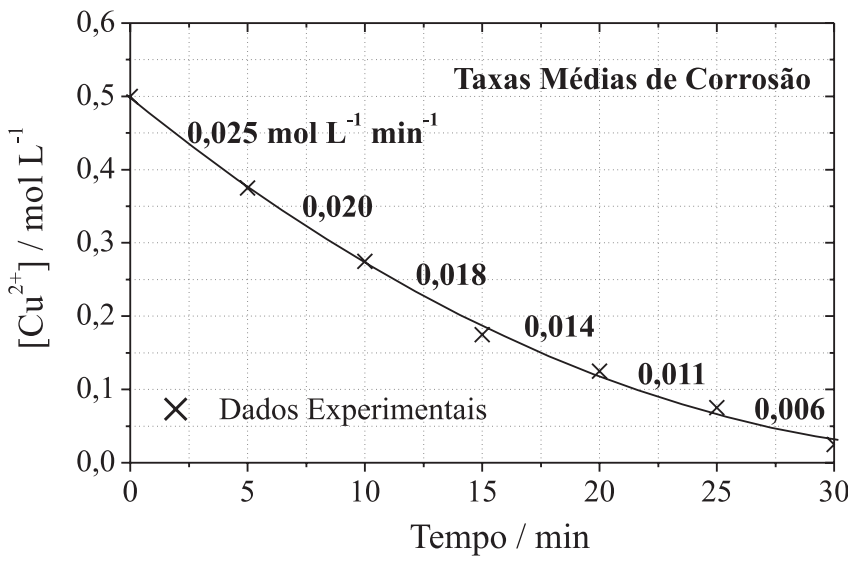

Figura 5. Variação da concentração de íons $\mathrm{Cu}^{2+}$ com o tempo de imersão

deste metal ser melhor cátodo que outros produtos de corrosão como os óxidos e sulfatos.

$$
\mathrm{O}_{2}(\mathrm{~g})+4 \mathrm{H}^{+}(\mathrm{aq})+4 \mathrm{e}^{-} \rightarrow 2 \mathrm{H}_{2} \mathrm{O}(\mathrm{l})
$$

\section{CONSIDERAÇÕES FINAIS}

O método apresentado é simples, rápido e quantitativo, quando não se requer muita precisão nos resultados. Permite avaliar a resistência à corrosão de chapas de aço galvanizado, de acordo com a espessura e a uniformidade do revestimento.

Os materiais e o reagente empregados são baratos e de fácil aquisição.
Quanto à aprendizagem, fornece conceitos e parâmetros importantes dos processos corrosivos, propicia a interação social entre os alunos viabilizada pelo trabalho em grupo e abre espaço para que o professor discuta com os alunos a respeito do fenômeno da corrosão como um processo natural que acontece no cotidiano.

\section{AGRADECIMENTOS}

\section{Às agências CNPq, FUNDUNESP e PROEX/UNESP.}

\section{REFERÊNCIAS}

1. ASTM; Standard Practice for Laboratory Immersion Corrosion Testing of Metals, ASTM G31-72, American Society for Testing and Materials: West Conshohocken, 1995, p. 95.

2. Gemelli, E.; Corrosão de Materiais Metálicos e sua Caracterização, $1^{\mathrm{a}}$ ed., LTC: Rio de Janeiro, 2001.

3. http://www.portaldagalvanizacao.com.br, acessada em Outubro 2011.

4. Aguiar, F. E. C.; Dissertação de Mestrado, Universidade Estadual Paulista "Júlio de Mesquita Filho", Brasil, 2003.

5. Panossian, Z.; Corrosão e Proteção Contra Corrosão em Equipamentos e Estruturas Metálicas, $1^{\text {a }}$ ed., IPT: São Paulo, 1993.

6. Martins, C. R.; de Andrade, J. B.; Quim. Nova 2002, 25, 259.

7. Magliavacca, D. M.; Teixeira, E. C.; Machado, A. C. de M.; Pires, M. R.; Quim. Nova 2005, 28, 371.

8. Gentil, V.; Corrosão, $5^{\text {a }}$ ed., LTC: Rio de Janeiro, 2007.

9. Chang, R.; Química Geral: Conceitos Essenciais, $4^{\mathrm{a}}$ ed., McGraw Hill: São Paulo, 2007.

10. ABNT; NBR 6323 - Galvanização de Produtos de Aço ou Ferro Fundido - Especificação, ABNT: Rio de Janeiro, 2007, p. 1. 